\title{
A 3D printed model for radius curvus surgical treatment planning in a $\operatorname{dog}^{1}$
}

\author{
João P.A. Bordelo ${ }^{2 *}$, Maria I.R. Dias ${ }^{2,3}$, Luís M.M.L. Cardoso², João M.F. Requicha ${ }^{4,5}$, \\ Carlos A.A. Viegas ${ }^{2,3}$ and Jean F. Bardet ${ }^{6}$
}

\begin{abstract}
Bordelo J.P.A., Dias M.I.R., Cardoso L.M.M.L., Requicha J.M.F., Viegas C.A.A. \& Bardet J.F. 2018. A 3D printed model for radius curvus surgical treatment planning in a dog. Pesquisa Veterinária Brasileira 38(6):1178-1183. Departamento de Ciências Veterinárias, Escola de Ciências Agrárias e Veterinárias, Universidade de Trás-os-Montes e Alto Douro, Quinta de Prados, 5000-801 Vila Real, Portugal. E-mail: joaopedrovet@live.com.pt

An 8 month-old, $10 \mathrm{~kg}$ male Azawakh dog was presented due to worsening forelimb gait and exercise intolerance. The right forelimb presented gross angular limb deformity with carpal valgus and radial procurvatum. Surgical planning based on radiographs allowed calculation of the centers of rotation and angularity (CORAs). The computer tomography data were used to generate 3D reconstructions of the antebrachium to aid the detection of the orthopaedic problems. With proper imaging software, the nature of the deformity and its degree were quantified using a previously unreported method based on the CORAs as a 3D printed model of anatomical area of interest. This 3D printed model was used by the surgeon to simulate the surgery with all orthopaedic steps, which included a partial ulna osteotomy and a double cuneiform osteotomy of the radius performed at the level of CORAs and stabilized with bone plates and screws. After 7 weeks, radiographs revealed bone union. At 8 months after surgery the animal presented a complete recovery of the involved forelimb. CORAs method combined with computed tomography and 3D model was useful to plan and simulate surgical procedures, including the corrective surgery of forelimb deformities in a dog which improved the surgical efficiency comparatively to the conventional pre-operative study.
\end{abstract}

INDEX TERMS: 3D printed model, radius curvus, surgery, dog, physical prototype simulation.

RESUMO.- [Modelo impresso em 3D usado num planeamento cirúrgico de um cão com radius curvus.] Um cão com 8 meses de idade, $10 \mathrm{~kg}$ de peso vivo, macho da raça Azawakh foi apresentado à clínica devido à intolerância ao exercício e agravamento da marcha do membro anterior. 0 membro anterior direito apresentou uma deformidade angular com valgus carpal e com um procarvatum radial. 0 planeamento

\footnotetext{
${ }^{1}$ Received on January 6, 2017.

Accepted for publication on June 2, 2017.

${ }^{2}$ Departamento de Ciências Veterinárias, Escola de Ciências Agrárias e Veterinárias, Universidade de Trás-os-Montes e Alto Douro (UTAD), Quinta de Prados, 5000-801 Vila Real, Portugal. *Corresponding author: joaopedrovet@live.com.pt

${ }^{3}$ Centro de Investigação e Tecnologias Agroambientais e Biológicas (CITAB), Universidade de Trás-os-Montes e Alto Douro (UTAD), Quinta de Prados, 5000-801 Vila Real, Portugal.

${ }^{4}$ Faculdade de Medicina Veterinária, Universidade Lusófona de Humanidades e Tecnologias, Campo Grande 376, 1749-024 Lisboa, Portugal.

${ }^{5}$ Biomateriais, Biodegradáveis e Biomiméticos (3B's), Universidade do Minho, Parque de Ciência e Tecnologia (Avepark), Zona Industrial da Gandra, 4805-017 Barco GMR, Portugal.

${ }^{6}$ Clinique Vétérinaire Dr. Bardet, 32 rue Pierret, 92200 Neuilly-sur-Seine, France.
}

cirúrgico inicialmente baseado em exames radiográficos possibilitou o cálculo dos centros de rotação e angulação articulares (CORAs). 0 exame de tomografia computadorizada foi utilizado juntamente com um software de imagiologia para obter o modelo 3D virtual da área anatómica de interesse que foi posteriormente impresso em 3D e que permitiu quantificar micrometricamente a deformação óssea presente. Este modelo 3D foi utilizado pelos cirurgiões para executar uma simulação cirúrgica completa que englobou todos os procedimentos cirúrgicos, que incluiu a realização de várias osteotomias e aplicação do material cirúrgico (placas e parafusos). Com base na simulação cirúrgica foi executada a cirurgia ao animal. Decorridas sete semanas, as radiografias demonstraram uma correta regeneração óssea. Oito meses após a cirurgia o animal apresentou uma recuperação completa. 0 método dos CORAs juntamente com a tomografia computadorizada e com a utilização do modelo 3D revelou-se útil no planeamento e na simulação dos vários procedimentos cirúrgicos, resultando numa melhoria significativa da eficiência cirúrgica.

TERMOS DE INDEXAÇÃO: Modelo impresso em 3D, cirurgia, cão, caninos, radius curvus. 


\section{INTRODUCTION}

Antebrachial growth deformities (AGD) are the most common skeletal malformations affecting dogs (Balfour et al. 2000, Sereda et al. 2009, Piras et al. 2012). They vary considerably regarding the clinical presentation, breed and body weight of the animal, etiology and time since the diagnosis. There are many possible presentations of radius curvus, but the most common is associated with a premature closing of the growth plates in a distal plan of the ulna and a cranial and lateral curvature of the radius extremity, with the presence of a valgus and an external rotation of the forelimb (Marcellin-Little et al. 1998, Quinn et al. 2000, Piras et al. 2012). Surgical correction is advised when there is a change in mobility, exercise intolerance or for prevention of secondary arthroses (Quinn et al. 2000, Fox et al. 2006, Sereda et al. 2009). Pre-operative planning has traditionally involved a method of deformity localization and quantification of the CORAs in the antebrachium of the dog obtained from orthogonal radiographs of the affected anatomical region. Usually, surgical treatment is based on an osteotomy with either an opening or a closing wedge technique (Crosse \& Worth 2010, Piras et al. 2012, Coutin et al. 2013). Surgical fixation can be obtained with numerous methods which have been used to stabilize the radial osteotomy, including external skeletal fixation, intramedullary pins, staples, dynamic compression plates (DCP) and screws, depending on animal factors and the surgeon's preference (Coutin et al. 2013). Although the ordinary radiographs may be helpful for pre-operative assessment in most of simple cases of radius curvus, animals with complex deformity may need more details for three-dimensional (3D) evaluation based on computed tomography scan (CT-scan) images in order to obtain an accurate surgical planning.

In this case report, a CT-scan, 3D imaging computer-aided design (CAD) model, rapid prototyping technology was used to do a complete pre-surgical plan. A surgical procedure was then simulated in the 3D physical model to increase the surgical accuracy.

\section{REPORT}

An 8 month-old Azawakh male dog with $10 \mathrm{~kg}$ and a body condition of $6 / 9$ was referred for orthopaedic consultation due to the aggravation of a right forelimb extremity deformation that had developed during the previous 2 months. Based on this history, the referring veterinarian suspected a radius curvus as the orthopedic deformation. On admission, the dog had an evident continuous right forelimb. General clinical examination was unremarkable normal and the animal did not present pain associated with the elbow manipulation. On the orthopedic exam, a forelimb lameness was evident with an important radius curvus deformation and associated with radius curvus, valgus and external carpal rotation, and with carpal hyperflexion while walking. Thus, imaging exams were performed to characterize and quantify the bone deformation. Standard orthogonal radiograph views of the right forelimb were obtained with the purpose of precisely determining the abnormal radius angulation. The dog was correctly positioned for orthogonal views of the elbows, antebrachium region and carpus. The obtained radiographies made possible to put articular axes and anatomic axes that guided the calculation of the CORAs (Fig.1A,B). The CORAs principle was used to determine the relationship between the anatomical axes of elbow and carpal joints (Fox et al. 2006). The craniocaudal radiographic projection (Fig.1A) revealed a carpian valgus with a $28^{\circ}$ rotation which also allowed verifying that the elbow was normal. The lateromedial projection (Fig.1B) allowed drawing two articular axes from the top of the proximolateral edge to the medial coronoid process, and between the distal points of the radiocarpian articular surface to the most medial surface of this bone structure. The craniocaudal projection allowed drawing a proximal articular axe and distal articular axe of radius that connect the most cranial to the most caudal point of radius head and the radiocarpian surface. Under the orthogonal projections, anatomic axes were marked in longitudinal lines which cut the metaphysis and shaft in two equal parts. CORAs are present in maximal curvature and result of the intersection of two longitudinal anatomic axes, and are calculated in a lateromedial radiographic projection. With this procedure, it was possible to confirm the presence of procurvatum of the radius. The centers of rotation and angulation method were not described in the ulna (Crosse \& Worth 2010, Piras et al. 2012). The identification of the anatomical landmarks for localisation and qualification of the CORAs could not always be achieved with an acceptable degree

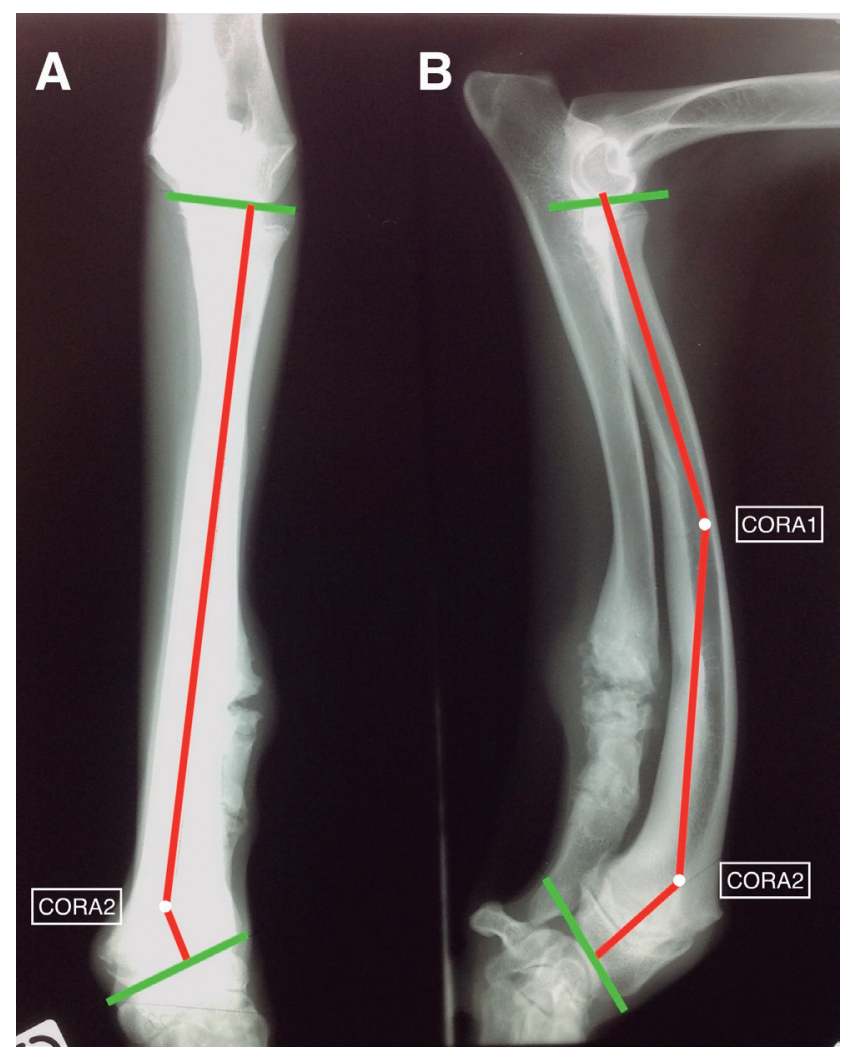

Fig.1. Radiographs of the right antebrachium with lines depicting the proximal and distal radial joint surfaces, (A) craniocaudal view and (B) lateromedial view, $90^{\circ}$ planes from the joint surfaces and the anatomical axes of the radius - CORAs. The obtained X-rays made possible to put articular axes (green lines) and anatomic axes (red lines) that guided the calculation of the CORAs. 
of accuracy (Coutin et al. 2013). Although confirming the presence of radius deformation with valgus, a detailed analysis of the radiographs made possible to identify the source problem with the presence of short ulna syndrome, a humeroulnar subluxation together with an osteoarthritis of the right carpus. In the present clinical case, an important ulna procurvarum was also observed. A CT-scan exam (GE Light-speed, GE Medical Systems, USA) was performed in a two-slice helical scanner on forelimbs with axial mode and $1 \mathrm{~mm}$ of thickness (Fig.2), while the dog was under general anesthesia. This imaging exam was crucial to perform a precise evaluation of the bone deformations of the right radius. It is unlikely to evaluate the radiocarpal join based only on orthogonal radiographic projections. The dog was positioned in sternal recumbency with both forelimbs extended cranially, which allowed the carpus, metacarpus and digits to lie in a neutral position. The $3 \mathrm{D}$ reconstruction allowed to detect and to calculate a $25^{\circ}$ external torsion of the radius. The bone deformations were compatible with radius curvus with external rotation, $25^{\circ}$ external torsion of the radius and carpian valgus with $28^{\circ}$, which was the main source of the existent locomotor problems of the patient. Under these circumstances, a surgical correction was decided.

This process starts with an image acquisition from imaging exams like computed tomography (, magnetic resonance imaging (MRI) and 3D ultrasonography, which allow to get the digital imaging and communications in medicine (DICOM) file. This file is processed in image processing software to visualize and obtain the 3D segmentation in a CAD software. The 3D model after a 3D modelling it is performed in 3D printer software to create a $3 \mathrm{D}$ printing file, which is send to a rapid prototype machines to result at the end in a 3D solid prototype by the addition of material layers.

Proper imaging CAD software (Surgicalvet, Newmedtech, Vila Real, Portugal) was used to obtain a 3D model of the anatomical area of interest (Fig.3). With this software, using in this case the Hounsfield units the DICOM was converted in a dynamic virtual 3D model with high accuracy. It gives the opportunity of surgeons to interact with the virtual 3D model and allows them to prepare a precise evaluation and study of the anatomic structures before surgery which could include a virtual realistic simulation. The micrometric precision of the virtual models can be reached with an accuracy of $1 \mu \mathrm{m}$ and the dynamic interaction gives the opportunity to interact and to perform a complex study more easily.

Initially, the 3D model allowed to confirm the antebrachial deformation detected with orthogonal views and with CT-scan. This virtual 3D model was printed in a fused depositing modelling (FDM) printer (Makerbot Replicator 2x, Stratasys USA). The 3D model made of acrylonitrile butadiene styrene (ABS) (Makerbot ABS filament, Startasys, USA) included the distal humerus, radius and ulna, and carpus (Fig.4).

The 3D printed model was used to simulate the surgical procedure including a double corrective osteotomy in a two-level correction located proximally to the humeroradial joint and then a second osteotomy located below the radiocarpal joint (Fig.5A,B). Afterwards, the surgeon tested the surgical material in the 3D model to rehearse the placement of bone plates, the casting bone plates and the selection of bone screws. As a

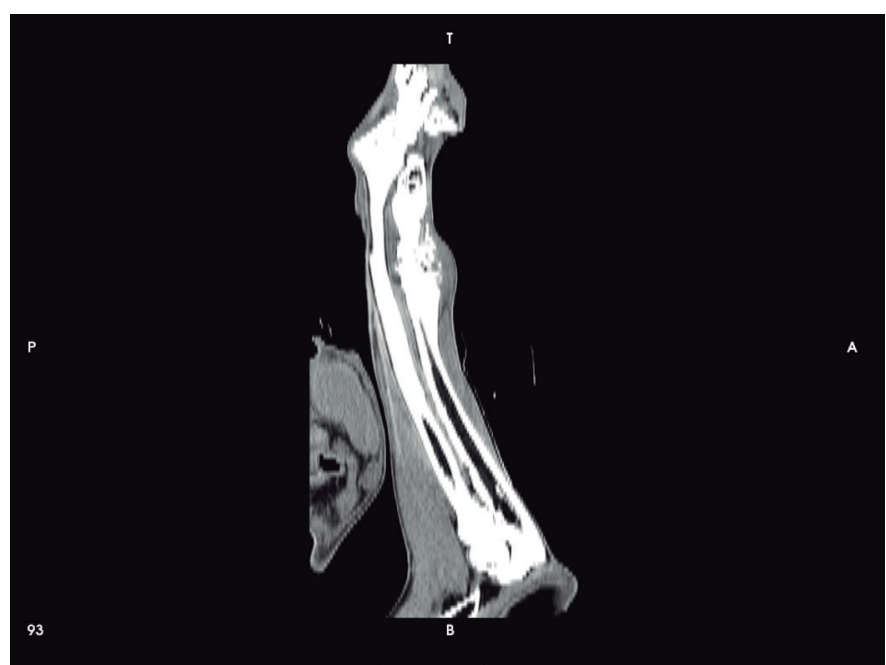

Fig.2. The CT sagittal plan scan of the right forelimb antebrachium which allow a precisely evaluation of the bone deformation of the right radius.

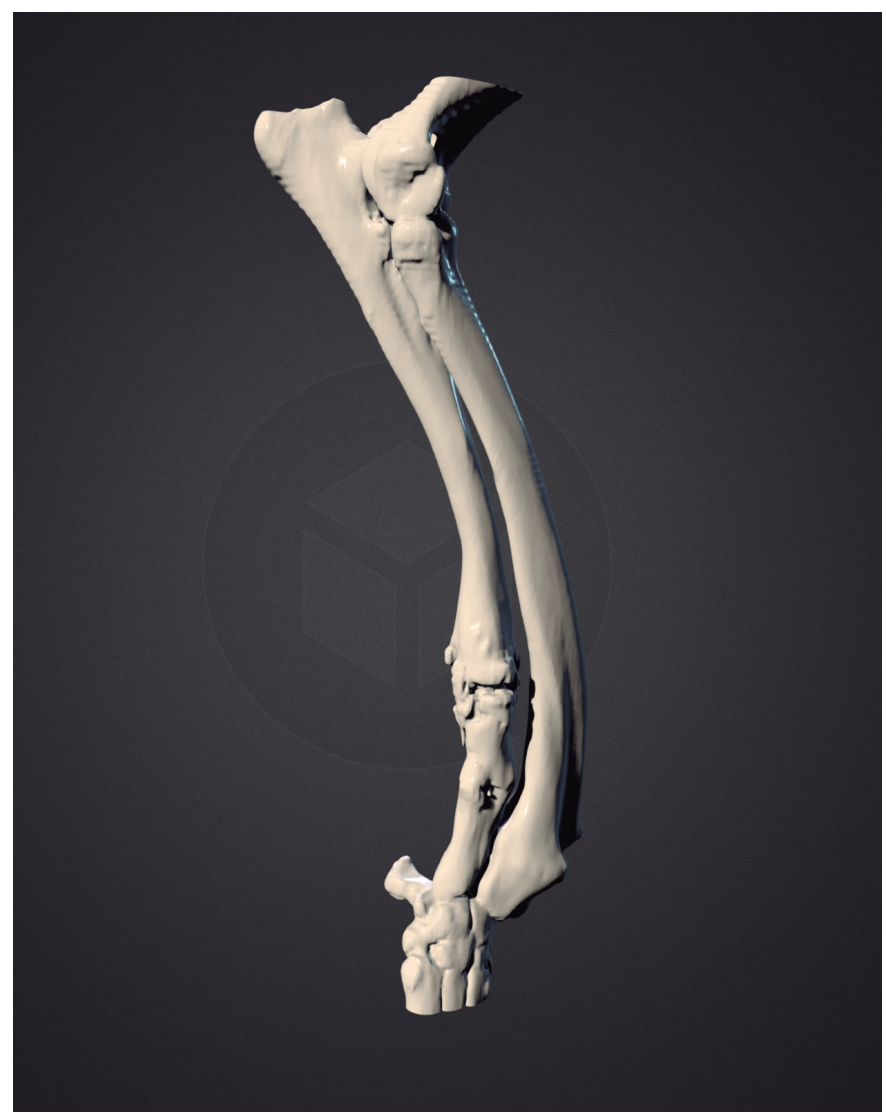

Fig.3. High accuracy 3D model created by commercial imaging CAD software, lateromedial view of the antebrachium of the right forelimb.

real surgical treatment, the osteotomies localizations were studied with CORA's and with CT-scan to assure a surgical procedure with the maximum accuracy in physical prototype. The surgeon performed the surgery simulation which consisted of a partial ulna osteotomy and a double cuneiform osteotomy 


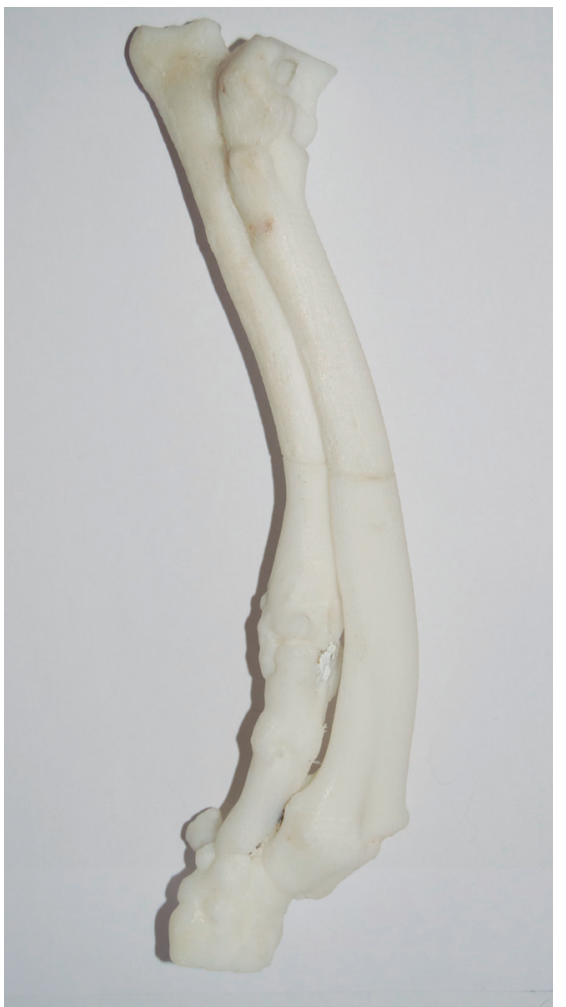

Fig.4. Printed 3D model in ABS, using a FDM printer, of the right forelimb antebrachium of the dog, lateral view. of the radius. The first radius osteotomy was proximal and was located $12 \mathrm{~cm}$ below to the humeroradial joint and the second one was made in a distal plan that was located $2.5 \mathrm{~cm}$ above the radiocarpal joint. The bone alignment was performed and fixed with a 3.5 DCP with six holes for the first osteotomy and another 3.5 DCP with five holes to the second osteotomy and corresponding 3.5 screws.

Orthogonal postoperative radiographs (Fig.6A,B) exhibited progression towards bony union at the osteotomy sites and the implants were static in position. Craniocaudal and lateral radiographic views were obtained and compared with the pre-operative orthogonal radiographic views to confirm that the rotational deformity of the radius was surgically corrected. In the postoperative period dog cephalexin was administered (Céphacare, Animalcare, USA), 20mg/kg orally, twice daily for 4 days, meloxicam (Metacam, Boehringer Ingelhein, Germany), 4mg/kg orally, twice daily for 5 days, and, for analgesia, tramadol (Topalgic, Sanofi-Aventis, France), $3 \mathrm{mg} / \mathrm{kg}$ orally, every 8 hours for 4 days. The dog was discharged after 5 further days and the owners were instructed to ensure the dog remained confined with only short lead walks for 7 weeks.

The animal was reassessed 7 weeks after surgery and up until then there was no evidence of complications, and the dog had almost reached a complete recovery. Within 8 months of postoperative medical evaluation, the dog did not have any intricacy, it had increased mobility and also exercise tolerance.

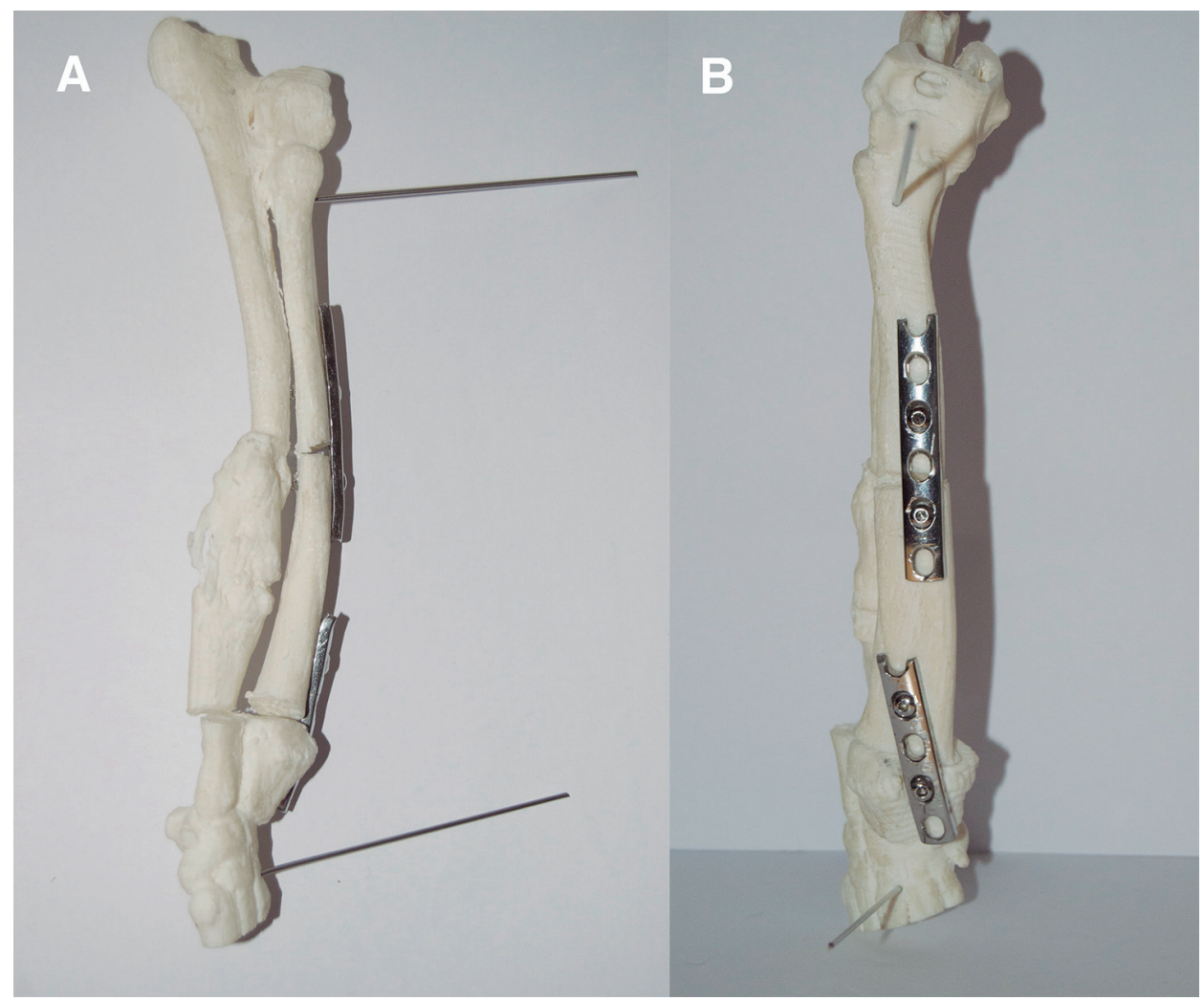

Fig.5. 3D model printed in ABS, using a FDM printer, of the right forelimb antebrachium of the dog which it was performed a real surgical simulation that included the osteotomy lines, alignment and placing of two osteosynthesis plates, (A) lateral view and (B) craniocaudal view. 


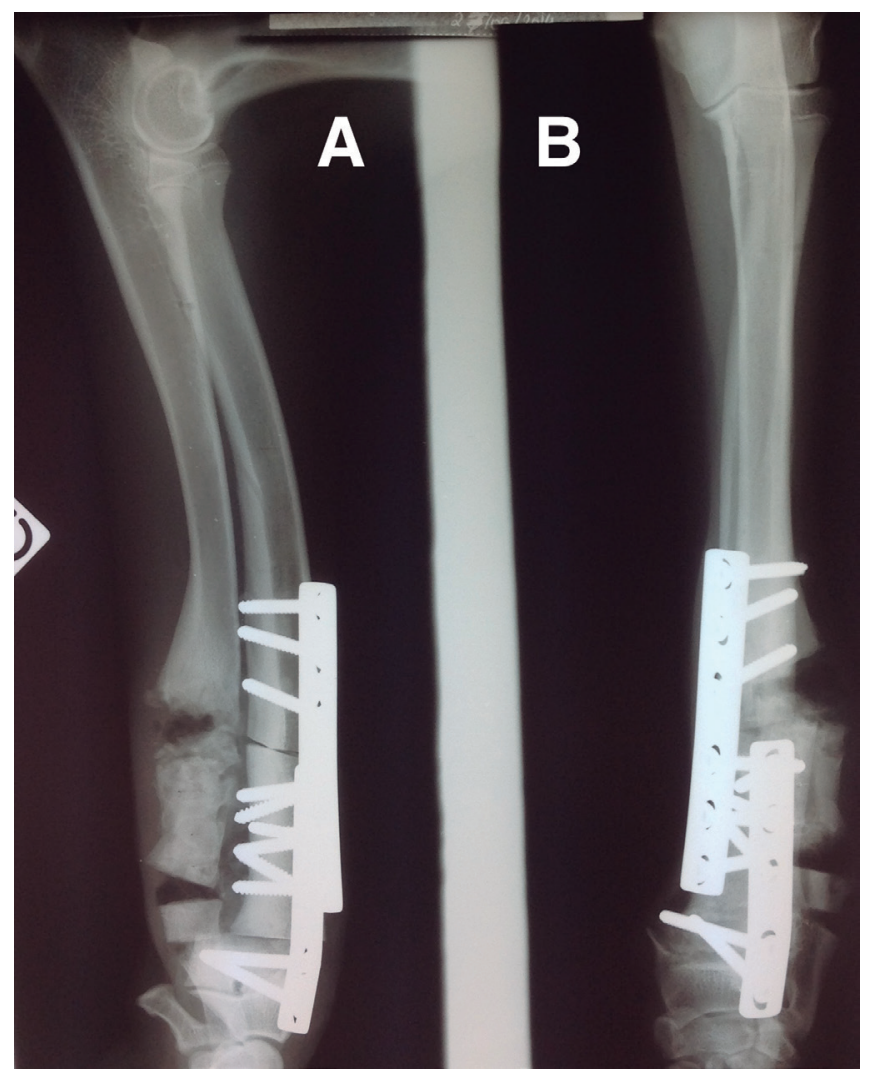

Fig.6. Postoperative radiological appearance after level corrective osteotomies and plates fixation. The carpal rotation has markedly improved. Joint planes and anatomic axes using the centre of rotation angle indicate correction in the frontal and sagittal planes, but a translational deformity remaining due to the level correction, (A) mediolateral view and (B) craniocaudal view.

\section{DISCUSSION}

Radius curvus with valgus clinical presentation is the most common deformation of the forelimb in the dog (Fox et al. 2006, Crosse \&Worth 2010). Asynchronous growth may cause deformities, such as procurvatum/recurvatum, valgus/varus, torsion and length discrepancies, resulting in joint incongruence, lameness, and degenerative joint disease (Fox et al. 2006, Coutin et al. 2013). Growth retardation of the ulna causes excessive radial procurvatum with external rotation, and carpal valgus, potentially resulting in osteoarthritis in the carpal and elbow joints (Balfour et al. 2000, Dismukes et al. 2008). The early surgical treatment is recommended in dogs with physeal injuries to minimize angular limb deformities to avoid their worsening (Rovesti et al. 2007). For these reasons, the animal in this case report was considered a surgery applicant.

Complex skeletal deformity disorders often demand time consuming surgery (Fox et al. 2006, Rovesti et al. 2007, Dismukes et al. 2008). Pre-operative planning tries to minimize the duration of orthopaedic surgery to reduce the risk of complications (Rovesti et al. 2007). Surgeons use generally imaging modalities like conventional radiographs and advance imaging technology such as CT-scan and MRI to support the planning process (Murase et al. 2008). An intra-operative assessment of the amount of correction needed, based on the CORAs method, must be very precise to obtain an accurate limb alignment (Dismukes et al. 2008, Piras et al. 2012). In this case, although the projection views helped the planning of the surgery, the CORAs calculation with this technique has low accuracy to study complex orthopedic deformations. A CT-scan was carried out to determine the limb torsion and to confirm the angulation centers. Even with the use of CT-scan, it is difficult for the surgeons to perform a correct surgical planning in this type of clinical presentation with multiple bone deformations (Dismukes et al. 2008, Crosse \& Worth 2010). Normally, 3D CT-scan image reconstruction aids the radiologist and the surgeons to better understand the clinical problem, but in more complex cases, such as antebrachial deformities, it does not allow for a perception of the orthopedic problem, because it is based in a 2D-plane visualization (Meola et al.2008). Even with this advantage, the 3D CT-scan reconstruction does not give doctors the possibility to do a realistic evaluation of the orthopedic anomaly (Crosse \& Worth 2010). Thus, in this clinical case, a virtual anatomical model was developed in a commercial software which increased the precision of the final model and the reliability of the anatomical structures, and with a dynamic capability that provide a complete interaction with all anatomical layers of the built 3D model. This helped to minimize the difficulty of the accurate isolation of the anatomical axes and helped the surgeon with the identification of the deformity axes.

The aggravated lameness source of this case report was an elbow joint and carpal joint osteoarthritis, elbow subluxation, consequences of any component of the antebrachial angulation as radialulnar rotation, procurvatum and valgus deformities.

Although bone plating does not allow for adjustments in alignment after surgery, as is the case with external skeletal fixation, the application of DCP has as advantage the ability to obtain stable fixation of a fracture line close to the end of a long bone, appearing ideal for the correction of angular deformities of the distal radius (Fox et al. 2006).

Rapid prototyping (RP) technologies are being frequently applied in the production of biological and anatomical models to support surgical training and planning tasks, as well as the development of prototypes to plan and simplify surgical procedures in fields as diverse as neurology, traumatology, and maxillofacial surgery (Petzold et al. 1999, Lantada \& Morgado 2012). In some cases, rapid customized prototyping supports or complements virtual 3D reconstruction technologies by helping implement physical test benches for surgical training (Mahaisavariya et al. 2006, Lantada \& Morgado 2012). With this new method, it is possible to do a pre-operative study with great accuracy including a real simulation of a surgical procedure, like osteotomies or preparation of surgical instruments, simultaneous with the advantage to achieve a one-step the treatment of this type of bone deformation (Mahaisavariya et al. 2006, Murase et al. 2008). In the current case, RP model planning was used to aid in the diagnosis and quantification of a severe antebrachial deformity that included a procurvatum and valgus and marked external rotation. The surgical treatment was crucial to limit the development of the carpal degeneration. In contrast, this dog was effectively treated with a one-stage procedure and there was minimal postoperative morbidity with rapid and improved limb use.

The combined use of CORA's, CT-scan and the 3D physical model allowed a precise evaluation of bone deformation, which is impossible to determine only with the orthogonal radiographic projections. Virtual simulations with computer software have been described in human surgery, and have 
been used for the orthopaedic treatments, for example cubitus varus and upper limb malunited fractures (Murase et al. 2008). Crosse \& Worth (2010) described the first clinical case in veterinary surgery using 3D CT data to simulate a surgery with computer software. Dismukes and collaborators (2008) described the first case report with 3D model used in surgical planning to treat a dog with radius curvus. Although this study demonstrates a valuable application of rapid prototyping technology which provided supplemental information for the diagnosis of and assessment of the severity of the deformity, the surgical planning of this case did not included the most useful step, the surgical simulation in the 3D printed model. In the present case, the great advantage of using this technology was the surgical simulation in 3D printed model which increased the surgeon's knowledge and confidence prior to surgery, promoted surgical efficiency, and potentially reduced the duration of surgery and anesthesia. Comparatively with the conventional surgical study based in corpses and in books, this new method of surgery simulation allows a realistic pre-operative study with a high accuracy (Murase et al. 2008, Crosse \& Worth 2010). This innovative method helps surgeons to decide the best surgical treatment option and gives them the opportunity to simulate the surgery procedures in a realistic 3D model of the clinical case (Mahaisavariya et al. 2006). In this clinical case, advanced imaging, computed-aided simulation, rapid prototype modelling and rehearsal surgery were used to improve the accuracy and confidence of the surgical treatment.

Although it reveals a considerable potential to apply this technology to planning and simulate the veterinary surgeries, it presented some limitations, like the long duration of the printing process if we consider emergency surgeries and the quality models which is insufficient for small models or for some medical specialities, like neurosurgery. Another limitation is the price of an anatomical model which at this time could be high for the majority of the surgeries.

\section{CONCLUSIONS}

This paper presents an innovative method for data obtained from CT-scan combined with a commercial digital CAD software and RP technology for surgical planning of difficult corrective osteotomy in one dog with an antebrachial deformity.

The new application enables the surgeon to choose the proper configuration and site of the osteotomy most appropriate for each dog.

\section{REFERENCES}

Balfour R.J., Boudrieau R.J. \& Gores B.R. 2000. T-plate fixation of distal radial closing wedge osteotomies for treatment of angular limb deformities in 18 dogs. Vet. Surg. 29(3):207-217. http://dx.doi.org/10.1053/jvet.2000.4396. PMid:10871222.

Coutin J.V., Lewis D.D., Kim S.E. \& Reese D.J. 2013. Bifocal femoral deformity correction and lengthening using a circular fixator construct in a dog.
J. Am. Anim. Hosp. Assoc. 49(3):216-223. http://dx.doi.org/10.5326/ JAAHA-MS-5836. PMid:23535751.

Crosse K.R. \& Worth A.J. 2010. Computer-assisted surgical correction of an antebrachial deformity in a dog. Vet. Comp. Orthop. Traumatol. 23(5):354361. http://dx.doi.org/10.3415/VCOT-10-01-0010. PMid:20740255.

Dismukes D., Fox D., Tomlinson J. \& Essman S.C. 2008. Use of radiographic measures and three-dimensional computed tomographic imaging in surgical correction of an antebrachial deformity in a dog. J. Am. Vet. Med. Assoc. 232(1):68-73. http://dx.doi.org/10.2460/javma.232.1.68. PMid:18167111.

Fox D.B., Tomlinson J.L., Cook J.L. \& Breshears L.M. 2006. Principles of uniapical and biapical radial deformity correction using dome osteotomies and the center of rotation of angulation methodology in dogs. Vet. Surg. 35(1):67-77. http://dx.doi.org/10.1111/j.1532-950X.2005.00114.x. PMid:16409412.

Lantada A.D. \& Morgado P.L. 2012. Rapid prototyping for biomedical engineering current capabilities and challenges. Annu. Rev. Biomed. Eng. 14(1):73-96. http://dx.doi.org/10.1146/annurev-bioeng-071811-150112. PMid:22524389.

Mahaisavariya B., Sitthiseripratip K., Oris P. \& Tongdee T. 2006. Rapid prototyping model for surgical planning of corrective osteotomy for cubitus varus: report of two cases. Injury Extra 37(5):176-180. http:// dx.doi.org/10.1016/j.injury.2005.10.026.

Marcellin-Little D.J., Ferretti A., Roe S.C. \& DeYoung D.J. 1998. Hinged Ilizarov external fixation for correction of antebrachial deformities. Vet. Surg 27(3):231-245. http://dx.doi.org/10.1111/j.1532-950X.1998.tb00122.x. PMid:9605235.

Meola S.D., Wheeler J.L. \& Rist C.L. 2008. Validation of a technique to assess radial torsion in the presence of procurvatum and valgus deformity using computed tomography: a cadaveric study. Vet. Surg. 37(6):525-529. http:// dx.doi.org/10.1111/j.1532-950X.2008.00399.x. PMid:19134101.

Murase T., Oka K., Moritomo H., Goto A., Yoshihawa H. \& Sugamoto K. 2008. Three-dimensional corrective osteotomy of malunited fractures of the upper extremity with use of a computer simulation system. J. Bone Joint Surg. Am. 90(11):2375-2389. http://dx.doi.org/10.2106/JBJS.G.01299. PMid:18978406.

Petzold R., Zeilhofer H.-F. \& Kalender W.A. 1999. Rapid prototyping technology in medicine: basics and applications. Comput. Med. Imaging Graphics 23(5):277-284. http://dx.doi.org/10.1016/S0895-6111(99)00025-7. PMid:10638658.

Piras L.A., Peirone B. \& Fox D. 2012. Effects of antebrachial torsion on the measurement of angulation in the frontal plane: a cadaveric radiographic analysis. Vet. Comp. Orthop. Traumatol. 25(2):89-94. http://dx.doi. org/10.3415/VCOT-10-09-0135. PMid:22286804.

Quinn M.K., Ehrhart N., Johnson A.L. \& Schaeffer D.J. 2000. Realignment of the radius in canine antebrachial growth deformities treated with corrective osteotomy and bilateral (Type II) external fixation. Vet. Surg. 29(6):558563. http://dx.doi.org/10.1053/jvet.2000.17852. PMid:11098789.

Rovesti G.L., Bosio A. \& Marcellin-Little D.J. 2007. Management of 49 antebrachial and crural fractures in dogs using circular external fixators. J. Small Anim. Pract. 48(4):194-200. http://dx.doi.org/10.1111/j.17485827.2006.00267.x. PMid:17381764.

Sereda C.W., Lewis D.D., Radasch R.M., Bruce C.W. \& Kirkby K.A. 2009. Descriptive report of antebrachial growth deformity correction in 17 dogs from 1999 to 2007, using hybrid linear-circular external fixator constructs. Can. Vet. J. 50(7):723-732. PMid:19794868. 